\title{
Development and Validation of a Method for Densitometric Analysis of Berberine in Herbal Extract and Polyherbal Formulation
}

\author{
V.K. Ghosh ${ }^{a}$ D.H. Nagore ${ }^{a} \quad$ M.J. Patil ${ }^{c} \quad$ A. Prakash ${ }^{b}$ \\ Departments of a Pharmacognosy and ${ }^{b}$ Pharmaceutical Chemistry, Dr. D.Y. Patil Institute of Pharmaceutical \\ Sciences and Research, University of Pune, Pimpri, and ' ${ }^{\mathrm{D}}$ Department of Pharmacognosy, Marathwada Mitra Mandal \\ College of Pharmacy, University of Pune, Pune, India
}

\section{Key Words}

High-performance thin-layer chromatography, validation •

Berberine $\cdot$ Berberis aristata

\begin{abstract}
Objective: To develop a new high-performance thin-layer chromatography (HPTLC) method for the quantification of berberine in herbal extract and pharmaceutical dosage form. Materials and Methods: The HPTLC was performed on aluminium foil plates coated with $200 \mu \mathrm{m}$ silica gel $60 \mathrm{~F}_{254}$. Linear ascending development with toluene:ethyl acetate:formic acid:methanol 9:9:3:1 (v/v/v/v) was performed at room temperature $\left(25 \pm 2{ }^{\circ} \mathrm{C}\right)$ in a twin-trough glass chamber saturated with mobile-phase vapour. Compact bands $\left(R_{F} 0.58 \pm 0.02\right)$ were obtained for berberine. Spectrodensitometric scanning was performed in fluorescence mode at $350 \mathrm{~nm}$. The method was validated for precision, recovery, robustness, specificity, and detection and quantification limits, in accordance with International Conference on Harmonization guidelines. Results: Linear regression analysis of the calibration plots showed a good linear relationship ( $\left.r^{2}=0.9996 \pm 0.0001\right)$ between peak area and concentration in the range 10-100 ng/band, respectively. The limits of detection and quantification were 2.8 and 9.3
\end{abstract}

\section{KARGER}

Fax +4161306 1234

E-Mail karger@karger.ch

www.karger.com
(C) 2010 S. Karger AG, Basel

$1011-7571 / 10 / 0196-0473 \$ 26.00 / 0$

Accessible online at:

www.karger.com/mpp ng/band. The recovery of the method was $98.5-100.6 \%$. Conclusion: The above method was a rapid and cost-effective quality-control tool for routine analysis of berberine in herbal extracts and in pharmaceutical dosage form.

Copyright $\odot 2010$ S. Karger AG, Basel

\section{Introduction}

Berberis aristata (Berberidaceae), commonly known as daruharidra, is commonly used in the Indian traditional system of medicine for the treatment of skin, ophthalmic and hepatic disorders $[1,2]$. Daruharidra is an official herbal drug in the treatment of skin disorders [3] and the plant is reported to possess tonic, stomachic, astringent, antiperiodic, diaphoretic, antipyretic and purgative components [4]. B. aristata root is mainly recognized for its isoquinoline alkaloids like berberine, barbamine, aromoline, karachine, palmatine, oxyacanthine, and oxyberberine [5]. Berberine is pharmacologically most active among the other phytoconstituents and exhibits antimicrobial, antidiabetic, hepatoprotective and anticancer activities [6-9].

A limited number of high-performance thin-layer chromatography (HPTLC) methods have been used for 
the quantitative determination of berberine in B. aristata [10] and in other plant extracts [11-13]. The berberine concentrations were also determined by UV spectrophotometry [14], ${ }^{1} \mathrm{H}$ NMR [15] and liquid chromatography coupled with different types of detectors [16-22]. Even though these analytical procedures are suitable for the detection of berberine in samples originating from plants, they have limitations with respect to their applications in the determination of berberine in plant samples. The reported colorimetric method lacks sensitivity and is tedious and time-consuming. Even though high-performance liquid chromatography (HPLC) is a method of choice, it is limited by extensive sample clean-up and requires expensive solvents and longer periods of column stabilization. In comparison to HPLC, HPTLC is a versatile analytical technique that requires less expensive instrumentation and expertise.

An earlier developed method based on HPTLC wherein berberine was detected in B. aristata and other plant extracts by using butanol:acetic acid:water as a developing solvent system was unsatisfactory because flow rate was slow, and it was reported to take about $4 \mathrm{~h}$ to run $10 \mathrm{~cm}$ [23]. The present study was therefore carried out to develop a rapid, sensitive and accurate analytical method for estimation of berberine in B. aristata and its pharmaceutical dosage form for the routine analysis of a large number of plant extract samples and their formulations.

\section{Materials and Methods}

\section{Chemicals and Standards}

The berberine standard was obtained from Yucca Enterprises, Mumbai, India. The daruharidra extract was purchased from Herbal Extract Supplier (Bangalore, India). Different marketed formulations containing daruharidra extract were obtained from a local market in the form of tablets and capsules. All the chemicals and reagents used were of analytical grade and were purchased from Merck Ltd, Mumbai, India.

\section{Preparation of Standard and Test Solution}

A stock solution of berberine was prepared in methanol at a concentration of $1 \mathrm{mg} / \mathrm{ml}$. The standard solutions were prepared from the stock solution by appropriate dilution with the same solvent. 20 tablets or capsules were weighed accurately and finely powdered. Powder equivalent to $50 \mathrm{mg}$ of daruharidra was accurately weighed and transferred to a $25 \mathrm{ml}$ volumetric flask and about $15 \mathrm{ml}$ of methanol was added. The flask was sonicated for 20 min in an ultrasonic water bath and diluted up to the mark with methanol. Then $1 \mathrm{ml}$ of this solution was transferred to a 10 $\mathrm{ml}$ volumetric flask and $9 \mathrm{ml}$ volume with methanol was added, then filtered through Whatman No. 41 filter paper and used for further chromatographic analysis.

\section{Chromatography}

The HPTLC was performed on $20 \times 10 \mathrm{~cm}$ aluminium foil plates coated with a $200 \mu \mathrm{m}$ layer of silica gel $60 \mathrm{~F}_{254}$ (E. Merck, Germany). Samples were applied as $6-\mathrm{mm}$ bands, by means of a Camag (Switzerland) Linomat 5 applicator fitted with a $100 \mu \mathrm{l}$ syringe. A constant application rate of $150 \mathrm{nl} / \mathrm{s}$ was used. Linear ascending development with toluene:ethyl acetate:formic acid:methanol 9:9:3:1 (v/v/v/v) as a mobile phase was performed in a glass twin-trough chamber (Camag) previously saturated with solvent for 5 min (optimized chamber saturation time) at room temperature and relative humidity $55 \pm 5 \%$. The development distance was $80 \mathrm{~mm}$. After development the plates were airdried. Densitometric scanning was then performed at $350 \mathrm{~nm}$ with a Camag TLC Scanner 3 in fluorescence mode operated by winCATS software (v. 1.4.3.6336). The slit dimension was $5 \times$ $0.45 \mathrm{~mm}$ with a scanning speed of $20 \mathrm{~mm} / \mathrm{s}$. The proposed method was validated as per International Conference on Harmonization guidelines [24].

\section{Linearity}

The stock solution $(10 \mu \mathrm{g} / \mathrm{ml})$ of berberine was prepared in methanol. Different volumes of the stock solution $(1,2,3,4,5,6$, $7,8,9$ and $10 \mu \mathrm{l}$ ) were located to a plate to provide $10,20,30,40$, $50,60,70,80,90$ and $100 \mathrm{ng}$ berberine/band, respectively. Each volume was applied three times on the TLC plate. Peak area data and the corresponding amounts were treated with linear leastsquare regression analysis.

\section{Method Validation}

Precision. The precision of the system was determined by measuring repeatability of sample application and measurement of peak areas for seven replicates of the same band (50 ng berberine/ band). To evaluate intra-day precision, seven samples at three different concentrations (30, 50 and $80 \mathrm{ng} /$ band) were prepared and analyzed on the same day. The inter-day precision was studied by comparing the assay performed on the three different days. Precision of the method was determined with the product against standard berberine. An amount of the product powder equivalent to $100 \%$ of the label claim of berberine was accurately weighed and assayed. The precision of the method and system were expressed as relative standard deviation (RSD, \%) and the standard error (SE) of peak area.

Robustness. Following the introduction of small changes in the mobile-phase composition ( $\pm 5 \%$ for each component), the effect on the result was examined. Mobile phases having different compositions, e.g. toluene:ethyl acetate:formic acid:methanol 8.5:9.5:3:1 v/v/v/v, 8.5:9:3.5:1 v/v/v/v, 8.5:9:3:1.5 v/v/v/v, 9.5:8.5:3:1 $\mathrm{v} / \mathrm{v} / \mathrm{v} / \mathrm{v}, 9.5: 9: 2.5: 1 \mathrm{v} / \mathrm{v} / \mathrm{v} / \mathrm{v}$, and 9.5:8.5:3:0.5 v/v/v/v were tried. The volume of mobile phase and duration of saturation investigated

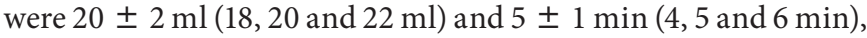
respectively. The robustness of the method was measured for three different amounts of berberine: 30, 50, and $80 \mathrm{ng} / \mathrm{band}$.

Limits of Detection and Quantification. Limits of detection (LOD) and quantification (LOQ) represent the concentration of the analyte that would yield signal-to-noise ratios of 3 for LOD and 10 for LOQ. The LOD and LOQ were determined by measuring the magnitude of the analytical background by spotting a blank and calculating the signal-to-noise ratio for berberine by spotting a series of solutions until the signal-to-noise ratio 3 for LOD and 10 for LOQ were obtained. To determine the LOD and 
LOQ, serial dilutions of standard solutions of berberine were made from the standard stock solution in the range of 1-100 ng/ spot. The diluted standard solutions were applied to a TLC plate and the chromatogram was run and the measured signal from the standard was compared to those of blank samples.

Recovery Study. Recovery study was performed to confirm accuracy and suitability of the method. The daruharidra placebo (identical formulation without active ingredient) was prepared in-house. The placebo samples were spiked at 80, 100 and $120 \%$ level of working concentration with standard berberine, then $5 \mu \mathrm{l}$ of each solution was applied on a TLC plate. The mixtures were analyzed $(n=6)$ by the proposed method.

Specificity. The specificity of the method was ascertained by analyzing a standard drug sample of equivalent concentration (50 ng/band) and placebo. The band for the berberine in the sample was confirmed by comparing the $R_{F}$ value and spectra of the band from the samples and from the standard as well as absence of any band in placebo in the same $R_{F}$ value also help in the confirmation of band for the standard. The peak purity of berberine was assessed by comparing the spectra at three levels, i.e. peak start, peak apex, and peak end.

Analysis of Herbal Extract and Pharmaceutical Dosage Form. Five microlitres of standard, daruharidra extract, tablet dosage form (B. aristata, Emblica officinalis, Rubia cordifolia and Acacia catechu) and placebo were spotted in the same plate $(20 \times 10 \mathrm{~cm})$, then developed and scanned by the proposed chromatographic conditions above. The analysis was repeated in triplicate. The possibility of interference of other phytoconstituents or excipients with the analysis was studied.

\section{Results}

A variety of mobile phases that included toluene:ethyl acetate, toluene:ethyl acetate:acetic acid, or toluene:ethyl acetate:formic acid were investigated for separation of the berberine spot from other components in herbal extract and excipients present in different commercial polyherbal formulations. The mixture toluene:ethyl acetate:formic acid:methanol 9:9:3:1 (v/v/v/v) yielded the most satisfactory resolution of berberine with good peak shape. The $R_{F}$ value for berberine was $0.58 \pm 0.02$, with resolution of 2.14. Pre-saturation of the TLC chamber with a mobile phase for 5 min ensured good migration reproducibility of berberine and better resolution.

\section{Linearity}

Calibration plots of peak area against concentration were linear in the range 10-100 ng for berberine. The calibration lines were represented by linear equation: $\mathrm{y}=$ $21.310+1,149.3 \mathrm{x}$, where $\mathrm{y}$ is response and $\mathrm{x}$ is amount (table 1). For this equation the correlation coefficient, $r^{2}$, was $0.9980 \pm 0.0003$.
Table 1. Summary of validation data for estimation of berberine in the herbal extract and its polyherbal formulations

\begin{tabular}{|c|c|c|c|}
\hline \multicolumn{3}{|l|}{ Parameters } & Berberine \\
\hline \multicolumn{3}{|c|}{ Linear range, ng/band } & $10-100$ \\
\hline \multicolumn{3}{|c|}{ Correlation coefficient, $r^{2}$} & 0.9996 \\
\hline \multicolumn{3}{|c|}{$\begin{array}{l}\text { Repeatability of sample application, } \%(n=7) \\
\text { Repeatability of measurement of peak area, } \%(n=7) \\
\text { Method precision, \% RSD }(n=6)\end{array}$} & $\begin{array}{l}0.20 \\
0.18 \\
0.22\end{array}$ \\
\hline \multicolumn{3}{|c|}{$\begin{array}{l}\text { Limit of detection } \\
\text { Limit of quantification }\end{array}$} & $\begin{array}{l}2.8 \mathrm{ng} \\
9.3 \mathrm{ng}\end{array}$ \\
\hline \multicolumn{3}{|l|}{ Specificity } & specific \\
\hline $\begin{array}{l}\text { Recovery study } \\
\text { Level }\end{array}$ & $\begin{array}{l}\text { Theoretical } \\
\text { yield, mg }\end{array}$ & $\begin{array}{l}\text { Actual yield, } \\
\text { mg }\end{array}$ & $\begin{array}{l}\% \text { recovery } \\
\pm \mathrm{SD}\end{array}$ \\
\hline $\begin{array}{l}80 \% \\
100 \% \\
120 \%\end{array}$ & $\begin{array}{l}2.0 \\
2.5 \\
3.0\end{array}$ & $\begin{array}{l}1.988 \\
2.515 \\
2.955\end{array}$ & $\begin{array}{r}99.46 \pm 0.27 \\
100.64 \pm 0.17 \\
98.52 \pm 0.15\end{array}$ \\
\hline
\end{tabular}

\section{Precision}

The RSD (\%) for the repeatability of the assay method, sample application (50 ng/band) and measurement of peak areas were $0.22,0.20$ and $0.18 \%$, respectively. Measurement of the peak area at three different concentrations resulted in low values of SE and RSD $(<1 \%)$ for inter- and intra-day variation, which suggested the precision of the method was excellent (table 2).

\section{Robustness}

The SD, RSD (\%) and SE of the peak area were calculated for changes in mobile-phase composition, mobilephase volume and duration of saturation at three concentration levels (30, 50 and $80 \mathrm{ng} / \mathrm{band})$. The low values of SD, RSD (\%) and SE obtained after introducing small deliberate changes in the method indicated the robustness of the method (table 3).

\section{$L O D$ and $L O Q$}

LOD represented the lowest concentrations of berberine that was detected, whereas the LOQ represented the lowest concentrations of berberine that was determined with acceptable precision and accuracy. The signal-tonoise ratios 3:1 and 10:1 were considered as LOD and LOQ, respectively. The LOD and LOQ were 2.8 and 9.3 ng/band for berberine. 
Fig. 1. a Comparison of spectra of berberine standard and berberine from extract and pharmaceutical dosage form. b Three-dimensional overlay chromatograms showing the specificity of the method in presence of standard berberine, daruharidra extract, polyherbal formulation and daruharidra placebo (x-axis: retention factor in the plate).

Table 2. Intra- and inter-day precision of the method $(n=7)$

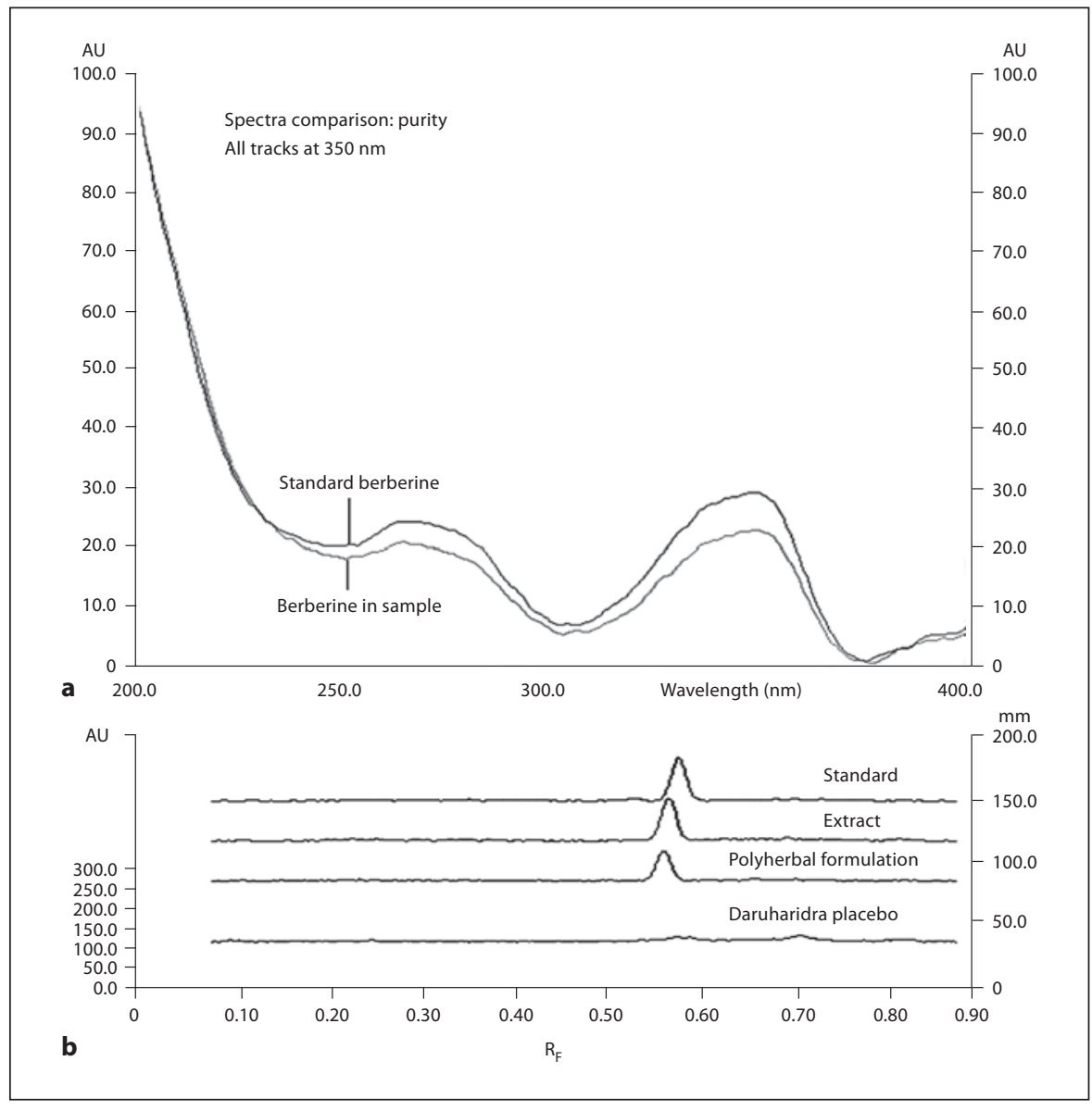

\begin{tabular}{|c|c|c|c|c|c|c|c|c|}
\hline \multirow{2}{*}{$\begin{array}{l}\text { Amount, } \\
\text { ng/band }\end{array}$} & \multicolumn{4}{|c|}{ Intra-day precision } & \multicolumn{4}{|c|}{ Inter-day precision } \\
\hline & mean area & SD & $\%$ RSD & SE & mean area & SD & $\%$ RSD & SE \\
\hline 30 & $1,787.57$ & 1.16 & 0.06 & 0.44 & $1,778.62$ & 1.61 & 0.09 & 0.61 \\
\hline 50 & $2,245.01$ & 1.63 & 0.07 & 0.62 & $2,235.76$ & 1.75 & 0.08 & 0.66 \\
\hline 80 & $2,786.71$ & 1.79 & 0.06 & 0.68 & $2,781.38$ & 1.57 & 0.06 & 0.59 \\
\hline
\end{tabular}

Table 3. Robustness of the method ( $\mathrm{n}=3 ; 30,50$ and $80 \mathrm{ng} / \mathrm{band})$

\begin{tabular}{llll}
\hline Condition & $\begin{array}{l}\text { SD of } \\
\text { peak area }\end{array}$ & \% RSD & SE \\
\hline $\begin{array}{l}\text { Mobile phase (toluene:ethyl } \\
\text { acetate:formic acid:methanol) }\end{array}$ & 1.79 & 0.082 & 1.03 \\
\hline $\begin{array}{l}\text { Mobile-phase volume } \\
(18,20 \text { and 22 ml) }\end{array}$ & 1.22 & 0.055 & 0.71 \\
\hline $\begin{array}{l}\text { Duration of saturation } \\
(4,5 \text { and 6 min) }\end{array}$ & 1.28 & 0.058 & 0.74 \\
\hline
\end{tabular}

\section{Recovery}

The percentage yield of daruharidra ranged from 98.5 to $100.6 \%$ as shown in table 1 . The obtained recovery values were within the limit recommended for chemical analysis, which indicate the reliability and reproducibility of the present method.

\section{Specificity}

The peak purity of berberine was assessed by comparing the spectra at peak start, peak apex and peak end positions of the spots, i.e. $r$ (start, middle) $=0.9959$ and 
$r$ (middle, end $)=0.9916$ and the overlain spectra are shown in figure 1a. This was further supported by good correlation $(r=0.9979)$ between the spectrum of standard berberine and the spectrum of berberine in polyherbal formulation.

\section{Analysis of Herbal Extract and Pharmaceutical Dosage Form}

The band of berberine was observed at $R_{F} 0.58$ in the chromatogram obtained from herbal extract and commercial polyherbal formulations. There was no interference from excipients or other components (fig. 1b). The developed HPTLC method was used to estimate berberine in five different commercial polyherbal formulations and the drug content was found to be $3.96 \pm 1.21 \% \mathrm{w} / \mathrm{w}$.

\section{Discussion}

HPTLC is gradually being used routinely as an analytical tool because of low operating cost, high sample throughput and minimum sample clean-up. The most important advantage of HPTLC is that more than one sample can be run at a time using a small quantity of mobile phase unlike HPLC. While the previously reported HPTLC methods $[10,12]$ that used a mobile phase composition of butanol:acetic acid:water on silica plate took about 2-3 h for development up to $6-8 \mathrm{~cm}$, the present method required only $30-45 \mathrm{~min}$ without compromising the resolution and peak shape. Equally important, the previously mentioned methods did not study the different variables in the HPTLC method which could affect reproducibility and sensitivity as we did. The low values of SE $(<1)$ in our method for all the variables confirmed that the method was robust. The LOD determination of berberine in both absorbance and fluorescence mode was helpful in deciding to add formic acid to the mobile phase because it drastically reduced the signal-to-noise ratio. Hence the low values of LOD and LOQ (2.8 and $9.3 \mathrm{ng} /$ band, respectively) obtained in this study were lower than those of previous methods $[10,12]$. The low LOD and LOQ values of our method were probably due to a baseline drift of the chromatogram.

The HPTLC method validation data suggest that the method had very good accuracy, precision and specificity with low LOD and a high level recovery value as compared to conventional HPTLC methods.

\section{Conclusion}

The newly developed HPTLC method for the quantification of berberine in B. aristata extract and its formulations was simple, rapid and easily adaptable for screening and quantitative determination. Hence we recommend the present method for rapid screening of a large number of plant extracts and routine quality control of formulations containing this compound.

\section{References}

1 Tripathi B: Charak-Samhita of Agnivesa, Elaborated by Charaka \& Drdhabala. Varanasi, Chaukhamba Surbharti Prakashan, 2008, vol 2, pp 299-338.

2 Nadkarni AK: Indian Materia Medica. Mumbai, Popular Prakashan Private Ltd, 2001, vol 1, pp 187-189.

3 The Ayurvedic Pharmacopoeia of India. Delhi, Government of India, Ministry of Health and Family Welfare, 1999, vol 2, pp 33-34.

4 Bone K: A Clinical Guide to Blending Liquid Herbs: Herbal Formulations for the Individual Patient. St Louis, Churchill Livingstone, 2003, pp 88-92.

5 Mukherjee PK: Quality Control of Herbal Drugs: An Approach to Evaluation of Botanicals. New Delhi, Business Horizons, 2002, pp 708-709.

\footnotetext{
Slobodnikova L, Alova DK, Abudova D, 11 Govindan M, Govindan G: A convenient Kotulva D, Kettmann V: Antimicrobial activity of Mohania aquifolium crude extract and its major isolated alkaloids. Phytother Res 2004;18:674-676.

7 Tang LQ, Wei W, Chen LM, Liu S: Effects of berberine on diabetes induced by alloxan and a high-fat/high-cholesterol diet in rats. J Ethnopharmacol 2006;108:109-115.

-8 Janbaz KH, Gilani AH: Studies on preventive and curative effects of berberine on chemical-induced hepatotoxicity in rodents. Fitoterapia 2000;71:25-33.

-9 Fukuda K, Hibiya Y, Mutoh M, Koshiji M, Akao S, Fujiwara $\mathrm{H}$ : Inhibition by berberine of cyclooxygenase- 2 transcriptional activity in human colon cancer cells. J Ethnopharmacol 1999;66:227-233. method for the determination of the quality of goldenseal. Fitoterapia 2000;71:232-235.

12 Rojsanga P, Gritsanapan W, Suntornsuk L: Determination of berberine content in the stem extracts of Coscinium fenestratum by TLC densitometry. Med Princ Pract 2006;15: 373-378.

13 Zhou H, Gu Y: Determination of berberine in Phellodendron chinense Schneid and its processed products by TLC densitometry. Zhongguo Zhong Yao Za Zhi 1995;20:405407.

14 El-Mastry S, Korany MA, Abou-Donia AH: Colorimetric and spectrophotometric determination of hydrastis alkaloids in pharmaceutical preparations. J Pharm Sci 1980;69: 597-598.
}

10 Rout KK, Pradhan S, Mishra SK: Estimation of berberine in ayurvedic formulations containing Berberis aristata. J AOAC Int 2008; 91:1149-1153. 
15 Li CY, Tsai SI, Damu AG, Wu TS: A rapid and simple determination of protoberberine alkaloids in rhizoma coptidis by ${ }^{1} \mathrm{H}$ NMR and its application for quality control of commercial prescriptions. J Pharm Biomed Anal 2009;49:1272-1276.

16 Brown PN, Roman MC: Determination of hydrastine and berberine in goldenseal raw materials, extracts, and dietary supplements by high-performance liquid chromatography with UV: collaborative study. J AOAC Int 2008;91:694-701.

17 Wenyan H, Li D, Yan C, Bin G, Jianchang H, Guili X: Determination of berberine in human plasma by liquid chromatography-electrospray ionization-mass spectrometry. J Pharm Biomed Anal 2007;44:931-937.
18 Qu HB, Ma YH, Yu K, Cheng YY: Development of an HPLC method for the quality evaluation of 'Ge-Gen-Qin-Lian' tablets derived from traditional Chinese medicine. Chromatographia 2007;65:713-718.

19 Chan CO, Chu CC, Moka DKW, Chau FT: Analysis of berberine and total alkaloid content in Cortex phellodendri by near infrared spectroscopy compared with high-performance liquid chromatography coupled with ultra-visible spectrometric detection. Analyt Chim Acta 2007;592:121-131.

20 Li HL, Zhang WD, Liu RH, Zhang C, Han T, Wang XW, Wang XL, Zhu JB, Chen CL: Simultaneous determination of four active alkaloids from a traditional Chinese medicine Corydalis saxicola Bunting (yanhuanglian) in plasma and urine samples by LC-MS-MS. J Chromatogr B Analyt Technol Biomed Life Sci 2006;831:140-146.
21 Wang Z, Du Q, Qiu X, Liu F, Tan F, Lan K, Jiang X, Jiang Q: Simultaneous determination of six herbal components in intestinal perfusate by high-performance liquid chromatography. Biomed Chromatogr 2009;23: 798-803.

22 Gupta PK, Hubbard M, Gurley B, Hendrickson HP: Validation of a liquid chromatography-tandem mass spectrometric assay for the quantitative determination of hydrastine and berberine in human serum. J Pharm Biomed Anal 2009;49:1021-1026.

23 Stahl E: Thin-Layer Chromatography: A Laboratory Handbook. New York, Springer, 2005, pp 733-732.

$24 \mathrm{ICH}, \mathrm{Q} 2 \mathrm{~A}$ (R1): Harmonized tripartite guideline. Text on validation of analytical procedures. IFPMA, Proceedings of International Conference on Harmonization, Geneva, November 2005 (http://www.ich.org/ LOB/media/MEDIA417.pdf). 